\title{
A Case of Hypogonadism Presented with Alopecia Universalis
}

A 46 year-old male patient attended our outpatient clinic complaining of hair falling out all over his body. He had developed hair loss first on his whole scalp and subsequently on his body. When the patient's anamnesis was explored further, it was found that he had also experienced a decline in both his sexual drive and levels of physical activity, hot flushes, sweating, and erection problems. The patient had already had these complaints when his alopecia started. His pubertal development was complete. He had no peculiarities in his personal and family history and was not using any medication. The physical examination was normal except for the total loss of hair all over his body (Figure 1). Routine laboratory tests were within normal limits. His total testosterone level was low at $142.1 \mathrm{ng} / \mathrm{dL}$ (250-836 $\mathrm{ng} / \mathrm{dL})$. The follicle-stimulating hormone (FSH) and luteinising hormone ( $\mathrm{LH}$ ) levels were normal at $1.05 \mathrm{mlU} / \mathrm{ml}(0-12.4 \mathrm{mIU} / \mathrm{mL})$ and $0.11 \mathrm{mlU} / \mathrm{mL}(0-8.6 \mathrm{mIU} /$ $\mathrm{mL})$, respectively. His hypophysis $M R$ and testis USG were normal. Based on clinical and laboratory results, he was diagnosed with idiopathic hypogonadotropic hypogonadism $(\mathrm{IHH})$. Following testosterone replacement treatment, his sexual drive and physical activity have increased. However, no improvement was seen in his alopecia, so the patient started photochemotherapy to treat this.

$\mathrm{IHH}$ occurs as a result of hypothalamo-pituitary axis dysfunction and is characterised by impaired spermatogenesis,

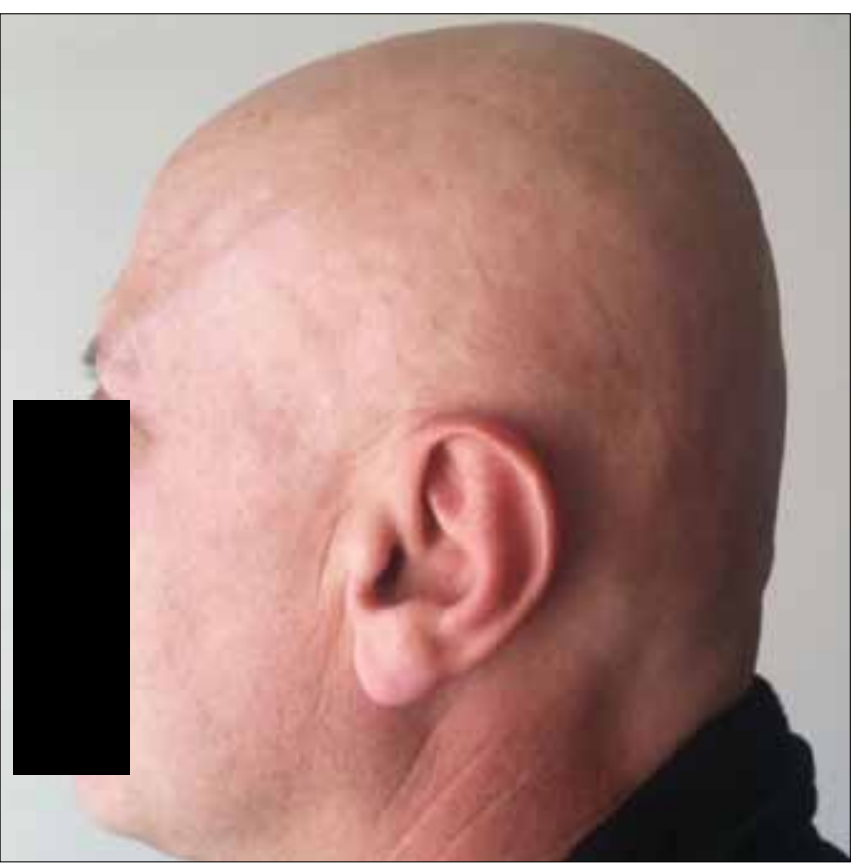

Figure 1. Total alopecia on the scalp and lateral portion of the eyebrows low testosterone levels, and low or normal levels of FSH and $\mathrm{LH}$. In hypogonadism, symptoms are variable, with the most common being poor libido. Patients may also present with complaints such as erectile dysfunction, depressive moods, lack of concentration, decreased physical performance, fatigue, changes in body composition, reduced frequency of shaving, and thinning of pubic and axillary hair (1). Since sex steroids impact the development of the immune system, the incidence of autoimmune diseases increases in hypogonadal conditions (2).

A few syndromic cases involving hypogonadism accompanied by partial alopecia areata have been reported. According to our current knowledge, our patient was the first case of a combination of alopecia universalis and hypogonadism without any accompanying syndromic components (such as diabetes mellitus, mental retardation, deafness, or ECG abnormalities) (3).

Yesilova et al. (4) evaluated the effect of gonadotropin treatment on immunologic characteristics in male patients with $\mathrm{IHH}$. The fact that the impaired immune parameters returned to normal levels after testosterone replacement was explained by the possible immune stabilisation effects of the gonadotropins.

Normal anagen hair follicles do not express major histocompatibility complex (MHC) class I and II antigens, and at the same time, Langerhans cell concentrations are low in these follicles (5). This shows that hair follicles are a privileged immune area. In the case presented, parallel to the decline in the levels of testosterone, the privileged immune mechanism of anagen hair follicles was thought to have been disabled, leading to alopecia.

In conclusion, although hypogonadism does not often occur in the pathogenesis of alopecia universalis and among accompanying diseases, we believe that patients with alopecia universalis should be examined for hypogonadism in addition to other possible accompanying autoimmune diseases.

Gökhan Celbek ${ }^{1}$, Hakan Turan², Yusuf Aydın², Fatih Ermiş ${ }^{4}$

${ }^{1}$ Department of Internal Internal Medicine,

Düzce University Faculty of Medicine, Düzce, Turkey

${ }^{2}$ Department of Dermatology, Düzce University Faculty of Medicine, Düzce, Turkey

${ }^{3}$ Department of Endocrinology, Düzce University Faculty of Medicine, Düzce, Turkey

${ }^{4}$ Department of Gastroenterology, Düzce University Faculty of Medicine, Düzce, Turkey

Address for Correspondence: Dr. Hakan Turan, Department of Dermatology, Düzce University Faculty of Medicine, Düzce, Turkey. 
Informed Consent: Informed consent was received from the participants of this study.

Peer-review: Externally peer-reviewed.

\section{References}

1. Araujo $A B$, Esche $G R$, Kupelian V, O'Donnell AB, Travison TG, Williams RE, et al. Prevalence of symptomatic androgen deficiency in men. J Clin Endocrinol Metab 2007;92:4241-7. [CrossRef]

2. Tanriverdi F, Silveira LF, MacColl GS, Bouloux PM. The hypothalamic-pituitary-gonadal axis: immune function and autoimmunity. J Endocrinol 2003;176:293-304. [CrossRef]
3. Woodhouse NJ, Sakati NA. A syndrome of hypogonadism, alopecia, diabetes mellitus, mental retardation, deafness, and ECG abnormalities. J Med Genet 1983;20:216-9. [CrossRef]

4. Yesilova Z, Ozata M, Kocar IH, Turan M, Pekel A, Sengul A, et al. The effects of gonadotropin treatment on the immunological features of male patients with idiopathic hypogonadotropic hypogonadism. J Clin Endocrinol Metab 2000;85: 66-70. [CrossRef]

5. Christoph T, Müller-Röver S, Audring H, Tobin DJ, Hermes B, Cotsarelis $G$, et al. The human hair follicle immune system: cellular composition and immune privilege. Br J Dermatol 2000;142: 862-73. [CrossRef] 